\title{
Outcomes of Treatment With CHOP and EPOCH in Patients With HIV Associated NHL in a Low Resource Setting
}

Clement Dove Okello ( $\nabla$ okdclement@gmail.com )

Uganda Cancer Institute https://orcid.org/0000-0003-4165-3051

Abrahams Omoding

Uganda Cancer Institute

Henry Ddungu

Uganda Cancer Institue

Yusuf Mulumba

Uganda Cancer Institute

Jackson Orem

Uganda Cancer Institute

Research article

Keywords: Treatment outcome DA-EPOCH CHOP HIV associated NHL low resource settings

Posted Date: August 5th, 2020

DOI: https://doi.org/10.21203/rs.3.rs-23153/v3

License: (c) (1) This work is licensed under a Creative Commons Attribution 4.0 International License. Read Full License

Version of Record: A version of this preprint was published on August 24th, 2020. See the published version at https://doi.org/10.1186/s12885-020-07305-2. 


\section{Abstract}

Background: The optimal chemotherapy regimen for treating HIV associated NHL in low resource settings is unknown. We conducted a retrospective study to describe survival rates, treatment response rates and adverse events in patients with HIV associated NHL treated with CHOP and dose adjusted-EPOCH regimens at the Uganda Cancer Institute.

Methods: A retrospective study of patients diagnosed with HIV and lymphoma and treated at the Uganda Cancer Institute from 2016 - 2018 was done.

Results: One hundred eight patients treated with $\mathrm{CHOP}$ and 12 patients treated with DA-EPOCH were analysed. Patients completing 6 or more cycles of chemotherapy were $51(47 \%)$ in the CHOP group and 8 $(67 \%)$ in the DA-EPOCH group. One year overall survival (OS) rate in patients treated with CHOP was $54.5 \%(95 \% \mathrm{Cl}, 42.8-64.8)$ and $80.2 \%(95 \% \mathrm{Cl}, 40.3-94.8)$ in those treated with DA-EPOCH. Factors associated with favourable survival were BMI $18.5-24.9 \mathrm{~kg} / \mathrm{m} 2,(p=0.03)$ and completion of 6 or more cycles of chemotherapy, $(p<0.001)$. The overall response rate was $40 \%$ in the $\mathrm{CHOP}$ group and $59 \%$ in the DA-EPOCH group. Severe adverse events occurred in $19(18 \%)$ patients in the CHOP group and $3(25 \%)$ in the DA-EPOCH group; these were neutropenia $(\mathrm{CHOP}=13,12 \%$; $\mathrm{DA}-\mathrm{EPOCH}=2,17 \%)$, anaemia $(\mathrm{CHOP}=12$, $12 \%$; DA-EPOCH=1, $\%$ ), thrombocytopenia ( $\mathrm{CHOP}=7,6 \%$; $\mathrm{DA}-\mathrm{EPOCH}=0)$, sepsis $(\mathrm{CHOP}=1)$, treatment related death $(\mathrm{DA}-\mathrm{EPOCH}=1)$ and hepatic encephalopathy $(\mathrm{CHOP}=1)$.

Conclusion: Treatment of HIV associated NHL with curative intent using CHOP and infusional DA-EPOCH is feasible in low resource settings and associated with $>50 \%$ one year survival.

\section{Background}

Globally, the estimated incidence of non-Hodgkin's lymphoma (NHL) was 5/100,000 in 2012(1). In Uganda, the incidence of NHL was 1,426/100,000 from the year 1991-2010(2). In 2016, an estimated 1.4 million people in Uganda were living with $\operatorname{HIV}(3)$. The incidence of $\mathrm{NHL}$ remains significantly higher in HIV-positive patients compared with the HIV negative patients, even in the era of combination antiretroviral therapy (ART) (4-7). The outcomes for patients with HIV-associated NHL and non-HIV associated $\mathrm{NHL}$ treated with chemotherapy in resource limited settings is still disappointingly low(8). Notwithstanding, the introduction of combination ART resulted in reduced morbidity and mortality from HIV infection(9-11), and improved NHL specific outcomes(12).

The optimal chemotherapy regimen for the treatment of HIV associated NHL in low resource settings is still unclear. First line chemotherapy regimens used to treat HIV associated NHL in the post ART era include, but not limited to the infusional cyclophosphamide-doxorubicin-etoposide (CDE) with complete remission rate (CR) of $42 \%$, median survival time of 17.8-month, and 1-year survival rate of $55 \%(13)$; and Cyclophosphamide, Doxorubicin, Vincristine and Prednisolone (CHOP) regimen with complete remission in $57.6 \%$ and $47 \%$ in patients treated with $\mathrm{R}-\mathrm{CHOP}$ and $\mathrm{CHOP}$ respectively, with an overall survival of about 35 months for R-CHOP and 28 months for $\mathrm{CHOP}(14)$. 
Dose adjusted Etoposide, Prednisone, Vincristine, Cyclophosphamide, and Doxorubicin (DA-EPOCH) infusional chemotherapy is a relatively recent combination in this category. Hitherto, it has been reported to achieve $79 \% \mathrm{CR}$ rate and $72 \%$ overall 2-year survival rate in patients with HIV associated $\mathrm{NHL}(15)$.

Use of the DA-EPOCH regimen has been suggested as unreasonable in low resource settings(16) possibly due to lack of infrastructure and supportive medications in addition to the demands of the 24 hour continuous infusion of this regimen. Uganda Cancer Institute (UCI) has in the recent past embarked on the use of DA-EPOCH regimen in a selected group of patients with HIV associated NHL. Due to the uncertainty regarding the optimum treatment of HIV associated $\mathrm{NHL}$ and the paucity of published data regarding the use of DA-EPOCH in resource limited settings, we undertook a retrospective study to describe the treatment outcomes in patients with HIV associated NHL treated with DA-EPOCH and CHOP regimens at the Uganda Cancer Institute.

\section{Methods}

\section{Study setting and design}

Charts of patients with a diagnosis of HIV and NHL treated with either CHOP or DA-EPOCH chemotherapy regimens at the Uganda Cancer Institute (UCI) from 2016 - 2018 were retrospectively studied. Additional therapy with rituximab is limited in Uganda due to its high cost. UCl is the only tertiary cancer treatment facility in Uganda. It receives patients from the entire country, with some patients traveling over $600 \mathrm{~km}$ to seek treatment. Diagnosis of $\mathrm{NHL}$ at the $\mathrm{UCl}$ is based on morphological examination of the haematoxylin and eosin (H\&E) stained tissues. Patients who can afford additional immunohistochemistry undertake them from private laboratories. Staging of $\mathrm{NHL}$ is based on the Ann Arbor staging system(17). There is no national medical insurance cover in Uganda. Aggressive HIV associated NHLs are treated with CHOP; however, since the year 2016, a selected group of patients have been treated with DA-EPOCH based on the physicians' judgement.

\section{Study procedure}

Charts of eligible patients were consecutively identified by the Records Officer. Patients treated with CHOP received cyclophosphamide $750 \mathrm{mg} / \mathrm{m}^{2} \mathrm{IV}$ on day 1 , doxorubicin $50 \mathrm{mg} / \mathrm{m}^{2} \mathrm{IV}$ bolus on day 1 , vincristine $1.4 \mathrm{mg} / \mathrm{m}^{2}$ IV bolus (max dose $2 \mathrm{mg}$ ) on day 1 , and prednisolone $60 \mathrm{mg} / \mathrm{m}^{2}$ orally on days $1-5$, repeated every 21 days for $6-8$ cycles on either outpatient or inpatient basis. Patients treated with DAEPOCH received etoposide $50 \mathrm{mg} / \mathrm{m}^{2}+$ doxorubicin $10 \mathrm{mg} / \mathrm{m}^{2} \mathrm{IV}+$ vincristine $0.4 \mathrm{mg} / \mathrm{m}^{2}$ infusion for 24 hours on days $1-4$, cyclophosphamide $750 \mathrm{mg} / \mathrm{m}^{2} \mathrm{IV}$ on day 5 , and prednisolone $60 \mathrm{mg} / \mathrm{m}^{2} \mathrm{PO}$ on days 15 on an inpatient basis; the DA-EPOCH dosages were adjusted based on nadir neutrophil counts in the preceding treatment cycle. All infusions were administered through peripheral intravenous lines. Normal saline was infused concurrently with the DA-EPOCH regimen through a Y-junction pot until the chemotherapy infusion was completed. No patient received rituximab or G-CSF. Data concerning additional medications, especially ART and Pneumocystis jiroveci pneumonia (PCP) were included. 
Adverse events were recorded at the time of each chemotherapy cycle and graded according to the $\mathrm{NCl}$ Common Terminology Criteria for Adverse Events (CTCAE) v5. In participants who had CT scans at baseline and end of therapy, treatment response was assessed using the Lugano Criteria but without the use of positron Emission Tomography. The last date of hospital review or death was recorded for survival analysis. Data was manually abstracted from charts using a standard data collection tool, coded, and then double entered into a computer using Epidata version 3.1 (Epidata association, Denmark) before exporting into STATA Version 14 (StataCorp, USA) for analysis.

\section{Study variables}

The study variables included participant's age and sex; type and stage of lymphoma, comorbidities, baseline ECOG performance score, body mass index (BMI), and number of chemotherapy cycles received, ART regimen and other additional concomitant medications received, and B-symptoms; nadir complete blood count (CBC) post chemotherapy and other adverse events, and disease response.

\section{DATA ANALYSIS}

Continuous variables were expressed as means and standard deviation (SD) if normally distributed or medians and inter quartile ranges (IQR) if skewed; categorical variables were described using frequencies and percentages; the overall treatment response rates (complete response, partial response) were estimated for both CHOP and DA-EPOCH chemotherapy arms using the binomial proportion and its $95 \%$ confidence interval as separate categories using the total number of participants enrolled at baseline as the denominator in each study arm. The proportion of patients who completed each treatment regimen were described as separate categories using the total number of participants enrolled at baseline as the denominator in each study arm. The one year overall survival rate was described for patients in the two treatment regimens using the Kaplan-Meier curves. Cox proportional hazards model was constructed to evaluate the association between patient characteristics and OS. Hazard ratios and $95 \%$ confidence intervals were generated, with hazard ratio $<1.0$ indicating survival benefit.

\section{Results}

\section{Baseline clinical characteristics}

Charts of 120 patients were identified (CHOP, $n=108$; DA-EPOCH, $n=12$ ). The commonest histological diagnosis in the DA-EPOCH group was DLBCL, 7(58\%) while for the CHOP group was Diffuse Large Cell lymphoma (DLCL), 65(60\%) (Table 1). Diagnosis of DLCL was obtained from the H\&E stain with no additional IHC. All patients in the DA-EPOCH group and a majority of patients in the CHOP group $(n=105 ; 97.2 \%)$ were already receiving ART prior to initiation of chemotherapy. Only 3 patients $(2.8 \%)$ in the CHOP group initiated ART after completion of their chemotherapy cycles. Ten patients (83\%) in the DA-EPOCH 
group were receiving tenofovir/lamivudine/efavirenz, one was receiving zidovudine/lamivudine/efavirenz, and the other was receiving tenofovir/lamivudine/nevirapine. Patients in the CHOP group received a variety of ART combination with 42 (39\%) patients receiving either tenofovir or zidovudine in combination with lamivudine and efavirenz. The rests of the patients received other combinations of first line ART. No patient had ART interrupted while receiving chemotherapy. All patients in the DA-EPOCH group and a majority of patients in the CHOP group ( $n=99,92 \%)$ were receiving cotrimoxazole for PCP prophylaxis. The rest were either on dapsone, or none. Markers for HIV control were not documented as these were collected at a separate ART treatment centre, independent of the UCI.

\section{TABLE 1: DEMOGRAPHIC FACTORS AND BASELINE CHARACTERISTICS}




\begin{tabular}{|c|c|c|c|}
\hline Variable & All patients $n=120$ & $\begin{array}{l}\text { CHOP, } \\
n=108\end{array}$ & $\begin{array}{r}\text { DA-EPOCH, } \\
\mathrm{n}=12\end{array}$ \\
\hline \multicolumn{4}{|l|}{ Sex, n(\%) } \\
\hline Male & $64(53)$ & $53(49)$ & $11(92)$ \\
\hline Female & $56(47)$ & $55(51)$ & $1(8)$ \\
\hline Mean age, years (SD) & $40(10)$ & $40(10.2)$ & $42(8.1)$ \\
\hline Mean BMI, $\mathrm{kg} / \mathrm{m}^{2}$ (SD) & $22(4.7)$ & $21(4.6)$ & $24(4.4)$ \\
\hline \multicolumn{4}{|l|}{ NHL type, n(\%) } \\
\hline DLBCL & $34(28)$ & $27(25)$ & $7(58)$ \\
\hline DLCL (IHC not done) & $69(58)$ & $65(60)$ & $4(33)$ \\
\hline PBL & $5(4)$ & $4(4)$ & $1(8)$ \\
\hline NHL Other & $9(8)$ & $9(8)$ & 0 \\
\hline Burkitt's & $3(3)$ & $3(3)$ & 0 \\
\hline \multicolumn{4}{|l|}{ ECOG score, n(\%) } \\
\hline 0 & $9(8)$ & $8(7)$ & $1(8)$ \\
\hline 1 & $29(24)$ & $22(20)$ & $7(58)$ \\
\hline 2 & $12(10)$ & $12(11)$ & 0 \\
\hline 3 & $7(6)$ & $6(6)$ & $1(8)$ \\
\hline Not assessed & $63(53)$ & $60(56)$ & $3(25)$ \\
\hline \multicolumn{4}{|l|}{ B-Symptoms } \\
\hline Yes & $65(54)$ & $58(54)$ & $7(58)$ \\
\hline No & $55(46)$ & $50(46)$ & $5(42)$ \\
\hline \multicolumn{4}{|l|}{ Comorbidity } \\
\hline Yes & $17(14)$ & $14(13)$ & $3(25)$ \\
\hline No & 103(86) & $94(87)$ & $9(75)$ \\
\hline \multicolumn{4}{|l|}{ Stage } \\
\hline I & $4(3)$ & $4(4)$ & 0 \\
\hline II & 21(18) & $17(16)$ & $4(33)$ \\
\hline III & $54(45)$ & $48(44)$ & $6(50)$ \\
\hline IV & $21(18)$ & $19(18)$ & $2(17)$ \\
\hline Not assessed & $20(17)$ & $20(19)$ & 0 \\
\hline
\end{tabular}

NB: DLBCL - Diffuse large B-cell lymphoma; DLCL - Diffuse large cell lymphoma; ECOG Easter Cooperative Oncology Group; IHC - Immunohistochemistry; PBL - Plasmablastic lymphoma; Comorbidity referred to the presence of any other diagnosis besides NHL.

\section{Treatment completion}

Fifty one (47\%) patients in the CHOP group and 8(67\%) patients in the DA-EPOCH group completed 6 or more cycles of chemotherapy. Those who completed 3-5 cycles were 
$31(29 \%)$ in the CHOP group and $1(8.3 \%)$ in the DA-EPOCH group. Three patients in each group received less than 3 cycles of chemotherapy. Reasons for non-completion of chemotherapy cycles were serious adverse events $(n=12,10 \%)$, other reasons $(n=4,3 \%)$, and were not described in 104(87\%) patients. Nineteen patients $(18 \%)$ in the CHOP group and $3(25 \%)$ in the DA-EPOCH group had serious adverse events detected. Most were laboratory adverse events like neutropenia $(\mathrm{CHOP}=13,12 \%$; DA-EPOCH=2, 17\%), anaemia $(\mathrm{CHOP}=12,12 \% ; \mathrm{DA}-\mathrm{EPOCH}=1,8 \%)$, and thrombocytopenia (CHOP=7, 6\%; DA$\mathrm{EPOCH}=0)$. Others were sepsis $(\mathrm{CHOP}=1)$, treatment related death $(\mathrm{DA}-\mathrm{EPOCH}=1)$ and hepatic encephalopathy $(\mathrm{CHOP}=1)$, (Table 2$)$. The lowest neutrophil count recorded was $0.12 \times 10^{\wedge} 3 / \mathrm{uL}$ after the first cycle of chemotherapy in a patient treated with DA-EPOCH.

Table 2: TREATMENT OUTCOMES

Variable

RESPONSE TO TREATMENT, $\mathrm{n}(\%)$

Complete response (CR)

Partial response (PR)

Progressive disease (PD)

No response assessment

ADVERSE EVENTS

Neutropenia, $\mathbf{n}(\%)$

Grade

$\leq$
3
4

Anaemia, n(\%)

Grade

$\leq 2$

3

Thrombocytopenia, $\mathbf{n}(\%)$
CHOP DA-EPOCH

$\mathrm{n}=108 \quad \mathrm{n}=12$

$29(27) \quad 5(42)$

$14(13) \quad 2(17)$

$15(14)$

1 (8)

$50(46)$

$13(12)$

2 (17)

$\begin{array}{rrr}\leq 2 & 0 & 0 \\ 3 & 6(6) & 2(17) \\ 4 & 7(6) & 0(0) \\ & 13(12) & 1(8)\end{array}$

$4(4)$

7 (6)

$0(0)$

$0(0)$ $\leq 2$

Other Adverse Events, n(\%)

Sepsis

Death

Hepatic Encephalopathy
$6(3)$

4 (3)

$0(0)$

1 (1)
$0(0)$

$0(0)$

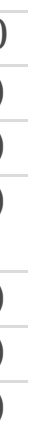


Note: Nadir levels of neutrophil, haemoglobin and platelet counts were recorded after each chemotherapy cycles; adverse events were classified using the NCI CTCAE v5.0

\section{Treatment response and survival}

Overall treatment response rate was $40 \%$ in the CHOP group and 59\% in the DA-EPOCH group. Complete response (CR) was achieved in 29(27\%) patients in the CHOP group and $5(42 \%)$ patients in the DA-EPOCH group. Partial response was observed in $14(13 \%)$ patients in the CHOP group and 2(17\%) patients in the DA-EPOCH group. (Table 3).

The entire study population had a one year (12 months) overall survival (OS) rate of $56.7 \%$ (95\% CI, 45.4-66.5), (Figure 1, Panel A). Patients treated with CHOP had a one year OS of 54.5\% (42.8-64.8) and those treated with DA-EPOCH of 80.2\% (95\% CI, 40.3-94.8), (Figure 1, Panel B). Subset analysis for patients with DLBCL showed a one year OS rate of $56.1 \%$ (95\% CI, 33.0-74.0) in the CHOP group and 100\% in the DA-EPOCH group. Predictors of survival were analysed using patients' age, sex, type of chemotherapy received, completion of 6 or more cycles of chemotherapy, type of lymphoma, stage of lymphoma, presence of Bsymptoms and comorbidities. At univariable analysis, factors that were associated with favourable survival were ECOG performance score of 3-4, BMI 18.5-24.9 kg/m² and completion of 6 or more cycles of chemotherapy. However, at multivariable analysis, only BMI 18.5-24.9 kg/m² (normal BMI), $(p=0.03)$ and completion of 6 or more cycles of chemotherapy, $(\mathrm{p}<0.001)$ were favourably associated with survival, Table 3.

\section{Discussion}

This retrospective study highlighted that treatment of HIV-associated NHL with curative intent using $\mathrm{CHOP}$ and infusional DA-EPOCH is feasible in a low resource setting.

The one year OS of patients treated with CHOP and DA-EPOCH in our study is comparable to other results in Africa. A study in Malawi reported a one year OS of $59.4 \%$ in patients with HIV-associated lymphomas treated with $\mathrm{CHOP}(18)$; in Botswana, the 1 year survival rate in patients with DLBCL was $52.8 \%$ following treatment with $\mathrm{CHOP}( \pm R)(19)$; a retrospective study in south Africa on patients with HIV associated DLBCL treated with CHOP and concomitant ART reported a 2 year OS of $40.5 \%(20)$. It has been noted that the outcomes of treating aggressive B cell NHL with chemotherapy appear to be similar in HIV-positive and HIV-negative populations especially in the era of combination ART $(7,21,22)$. Some studies report a 
CD4 count $<100 /$ uL as a negative prognostic finding $(14,23)$. However, our study did not have data on CD4 counts.

Normal BMI and completion of 6 or more cycles of chemotherapy were associated with favourable survival in our study. A retrospective study on HIV associated lymphomas in Nigeria reported stage of lymphoma as the only factor predictive of survival(24). Other factors that have been noted to predict survival include type of lymphoma(25), age, ECOG performance scores, stage of lymphoma and LDH level(26).

We acknowledge that the observed differences in OS and response rates between the CHOP and DAEPOCH groups in our study does not demonstrate any real differences given the different characteristics of the patients, and especially the small number of patients in the EPOCH group. However, the initial study on DA-EPOCH in patients with DLBCL reported better OS rate at 62 months of $73 \%$ than with $\mathrm{CHOP}(27)$. Subsequent addition of Rituximab to DA-EPOCH produced even better results of a 12-month PFS rate of $85 \%(28,29)$. Additionally, a study by the AIDS-Malignancies Consortium Trial 010, a phase 3 trial of $\mathrm{CHOP}$ vs R-CHOP in patients with HIV-associated $\mathrm{NHL}$ showed a better $\mathrm{CR}$ of $47 \%$ for $\mathrm{CHOP}(14)$ than was observed in our study (27\%).

Other studies on the treatment of HIV associated NHL with CHOP or DA-EPOCH in the sub-Saharan Africa show similar results with our study. De Witt (2013) in their retrospective study on patients with HIV associated DLBCL treated with CHOP $(n=34)$ and CHOP-like $(n=2)$ regimens in south Africa reported CR of $38.9 \%(20)$. A smaller study in Malawi $(n=12)$ on patients with plasmablastic lymphoma in HIV positive $(n=6)$ and HIV negative patients $(n=6)$ in which 8 patients were treated with CHOP and 4 patients were treated with modified DA-EPOCH reported an overall $\mathrm{CR}$ in $42 \%$ of the patients ( $\mathrm{CHOP}=25 \%$; DA$\mathrm{EPOCH}=75 \%)(30)$. In another retrospective study in south Africa where only 4 cases $(<1 \%)$ were HIV $(+)$ and no specific chemotherapy regimens were defined, the overall CR range was $46-75 \%$ for all subtypes of $\mathrm{NHL}(31)$; and in a large retrospective study of paediatric Burkitt's Lymphoma in Uganda where 70 of the 228 patients were HIV positive with a mean age of 6.7 years and no specific chemotherapy was mentioned, CR was $36 \%(32)$.

The low completion rate of chemotherapy in our study may have partly contributed to the low treatment response rates. However, adverse events contributed to non-completion of chemotherapy in only $10 \%$ of the patients whereas a majority of patients did not have clearly documented reasons for non-completion of chemotherapy.

Haematological adverse events (AEs) were the most prevalent in our study population. However, this should be taken with caution due to the limitation associated with data abstraction from patient charts that may not easily capture non lab based AEs. Takondwa et al.(30) in their study in Malawi reported treatment delays in patients receiving DA-EPOCH $(n=4 / 4)$ and patients treated with $\mathrm{CHOP}(n=4 / 8)$ due to grade $3 / 4$ neutropenia and grade 3 anaemia $(\mathrm{CHOP}=1)$. It is possible that the small number of patients in our study and that by Takondwa et al.(30) may not have been sufficient to adequately evaluate the AEs. 
Despite the infusion of DA-EPOCH through peripheral lines, there were no other major documented concerns in the patients who received it.

To the best of our knowledge, our study is one of the few studies to describe CHOP and DA-EPOCH regimens in the treatment of HIV associated NHL in the sub-Saharan Africa. However, we acknowledge the following limitations: the imbalance between the two groups in terms of the sample size and the other baseline characteristics that limited meaningful comparisons, inadvertent patient selection bias to the treatment groups - moreover, recent treatment approaches might have favoured patients treated with DA$\mathrm{EPOCH}$, lack of HIV characteristics, limited data on chemotherapy toxicities that might have resulted from inadequate documentation by the treating physicians, and lack of immunohistochemistry to refine the diagnosis. It is possible that some patients who were treated with the $\mathrm{CHOP}$ regimen might have had more aggressive histological subtypes of NHL such as Burkitt lymphomas or plasmablastic lymphomas that were treated inadequately. $\mathrm{CHOP}$ regimen is considered less intensive and therefore inadequate for the treatment of Burkitt lymphoma $(33,34)$ and Plasmablastic lymphoma (35). All these may limit the generalizability of our findings.

\section{Conclusions}

This study showed that treatment of HIV-associated $\mathrm{NHL}$ with curative intent using $\mathrm{CHOP}$ and infusional DA-EPOCH is feasible in low resource settings and associated with $>50 \%$ one year survival. Additional studies are required to prospectively explore this observation in similar settings.

\section{Abbreviations}

ART: Antiretroviral Therapy; CHOP: Cyclophosphamide, Doxorubicin, Vincristine and Prednisolone; CTEPAERS: $\quad$ Cancer Therapy Evaluation Program Adverse Event Reporting System; EPOCH: Etoposide, Doxorubicin, Vincristine, Cyclophosphamide, and Prednisone; HIV: Human Immunodeficiency Virus; UCl: Uganda Cancer Institute.

\section{Declarations}

\section{Ethics approval and consent to participate}

Waiver of consent and study approvals were obtained from the Uganda Cancer Institute Research Ethics Committee (Reference number: 15-2018) and the study was registered at the Uganda National Council for Science and Technology (Reference number: HS 2568).

\section{Consent for publication}

Not applicable

\section{Availability of data and materials}


All data generated or analysed during this study are included in this published article

\section{Competing interests}

All the authors have declared no conflicts of interest.

\section{Funding}

This work was funded by a Conquer Cancer Foundation of ASCO Global Oncology Young Investigator Award. Any opinions, findings, and conclusions expressed in this material are those of the author(s) and do not necessarily reflect those of the American Society of Clinical Oncology ${ }^{\circledR}$ or the Conquer Cancer Foundation. The funding source had no direct roles in the design of this protocol, data collection, analysis and interpretation, and manuscript writing.

\section{Authors' contributions}

CDO: Wrote the manuscript. AO: Reviewed the manuscript; HD; Reviewed the manuscript; YM: Analysed data and reviewed the manuscript; JO: Reviewed the manuscript. All authors read and approved the final manuscript.

\section{Acknowledgements}

We thank all the patients whose information were used for this study. We also thank all the study staffs especially Joweria Kakembo and her team for retrieving the charts and data abstraction, and Bridget Angucia for data entry and clean up. We also thank Thomas S. Uldrick and Edus H. Warren for the thorough review of the manuscript.

\section{Authors' details}

${ }^{1}$ Uganda Cancer Institute

\section{References}

1. Ferlay J, Soerjomataram I, Ervik M, Dikshit R, Eser S, Mathers C, et al. GLOBOCAN 2012 v1. 0, Cancer Incidence and Mortality Worldwide: IARC CancerBase No. 11. Lyon, France: International Agency for Research on Cancer; 2013. 2015.

2. Wabinga HR, Nambooze S, Amulen PM, Okello C, Mbus L, Parkin DM. Trends in the incidence of cancer in Kampala, Uganda 1991-2010. International journal of cancer. 2014;135(2):432-9.

3. UNAIDS (2017) 'Data Book'.

4. Little RF, Gutierrez M, Jaffe ES, Pau A, Horne M, Wilson W. HIV-associated non-Hodgkin lymphoma: incidence, presentation, and prognosis. Jama. 2001;285(14):1880-5.

5. Coté TR, Biggar RJ, Rosenberg PS, Devesa SS, Percy C, Yellin FJ, et al. Non-Hodgkin's lymphoma among people with AIDS: incidence, presentation and public health burden. International journal of 
cancer. 1997;73(5):645-50.

6. Matthews GV, Bower M, Mandalia S, Powles T, Nelson MR, Gazzard BG. Changes in acquired immunodeficiency syndrome-related lymphoma since the introduction of highly active antiretroviral therapy. Blood. 2000;96(8):2730-4.

7. Sabin C, Smith C, d Arminio Monforte A, Battegay M, Gabiano C, Galli L, et al. Collaboration of Observational HIV Epidemiological Research Europe (COHERE) Study Group: Response to combination antiretroviral therapy: variation by age. AIDS. 2008;22:1463-73.

8. Bateganya MH, Stanaway J, Brentlinger PE, Magaret AS, Wald A, Orem J, et al. Predictors of survival after a diagnosis of non-Hodgkin's lymphoma in a resource-limited setting: a retrospective study on the impact of HIV infection and its treatment. Journal of acquired immune deficiency syndromes (1999). 2011;56(4):312.

9. Noy A. Update in HIV lymphoma. Current opinion in oncology. 2006;18(5):449-55.

10. Sparano JA. HIV-associated lymphoma: the evidence for treating aggressively but with caution. Current opinion in oncology. 2007;19(5):458-63.

11. Levine AM. Management of AIDS-related lymphoma. Current opinion in oncology. 2008;20(5):522-8.

12. Gopal S, Patel MR, Yanik EL, Cole SR, Achenbach CJ, Napravnik S, et al. Association of early HIV viremia with mortality after HIV-associated lymphoma. AIDS (London, England). 2013;27(15):2365.

13. Sparano JA, Lee S, Henry DH, Ambinder RF, von Roenn JH, Tirelli U. Infusional cyclophosphamide, doxorubicin, and etoposide in HIVassociated non-Hodgkin's lymphoma: a review of the Einstein, Aviano, and ECOG experience in 182 patients. JAIDS. 2000;23(A11).

14. Kaplan LD, Lee JY, Ambinder RF, Sparano JA, Cesarman E, Chadburn A, et al. Rituximab does not improve clinical outcome in a randomized phase 3 trial of CHOP with or without rituximab in patients with HIV-associated non-Hodgkin lymphoma: AIDS-Malignancies Consortium Trial 010. Blood. 2005;106(5):1538-43.

15. Little R, Pearson D, Gutierrez M, Steinberg S, Yarchoan R, Wilson W. DOSE-ADJUSTED EPOCH CHEMOTHERAPY (CT) WITH SUSPENSION OF ANTIRETROVIRAL THERAPY (ART) FOR HIVASSOCIATED NON-HODGKIN'S LYMPHOMA (HIV-NHL): ABSTRACT S16. JAIDS Journal of Acquired Immune Deficiency Syndromes. 2000;23(3):A11.

16. Ulrickson M, Press OW, Casper C. Epidemiology, diagnosis, and treatment of HIV-associated nonHodgkin lymphoma in resource-limited settings. Advances in hematology. 2012;2012.

17. Armitage JO. Staging non-Hodgkin lymphoma. CA Cancer J Clin. 2005;55:368-76.

18. Gopal S, Fedoriw Y, Kaimila B, Montgomery ND, Kasonkanji E, Moses A, et al. CHOP chemotherapy for aggressive non-Hodgkin lymphoma with and without HIV in the antiretroviral therapy era in Malawi. PLoS One. 2016;11(3).

19. Milligan MG, Bigger E, Abramson JS, Sohani AR, Zola M, Kayembe MK, et al. Impact of HIV infection on the clinical presentation and survival of non-Hodgkin lymphoma: A prospective observational study from Botswana. Journal of global oncology. 2018;4:1-11. 
20. De Witt P, Maartens DJ, Uldrick TS, Sissolak G. Treatment outcomes in AIDS-related diffuse large Bcell lymphoma in the setting roll-out of combination antiretroviral therapy in South Africa. Journal of acquired immune deficiency syndromes (1999). 2013;64(1):66.

21. Spagnuolo V, Galli L, Salpietro S, Gianotti N, Guffanti M, Cossarini F, et al. Ten-year survival among HIV-1-infected subjects with AIDS or non-AIDS-defining malignancies. International journal of cancer. 2012;130(12):2990-6.

22. Barta SK, Samuel M, Xue X, Wang D, Lee J, Mounier N, et al. Changes in the influence of lymphomaand HIV-specific factors on outcomes in AIDS-related non-Hodgkin lymphoma. Annals of Oncology. 2015;26(5):958-66.

23. Little RF, Pittaluga S, Grant N, Steinberg SM, Kavlick MF, Mitsuya H, et al. Highly effective treatment of acquired immunodeficiency syndrome-related lymphoma with dose-adjusted EPOCH: impact of antiretroviral therapy suspension and tumor biology. Blood. 2003;101(12):4653-9.

24. Silas OA, Achenbach CJ, Hou L, Murphy RL, Egesie JO, Sagay SA, et al. Outcome of HIV-associated lymphoma in a resource-limited setting of Jos, Nigeria. Infectious agents and cancer. 2017;12(1):34.

25. Han X, Jemal A, Hulland E, Simard EP, Nastoupil L, Ward E, et al. HIV infection and survival of lymphoma patients in the era of highly active antiretroviral therapy. Cancer Epidemiology and Prevention Biomarkers. 2017;26(3):303-11.

26. Project IN-HsLPF. A predictive model for aggressive non-Hodgkin's lymphoma. New England Journal of Medicine. 1993;329(14):987-94.

27. Wilson WH, Grossbard ML, Pittaluga S, Cole D, Pearson D, Drbohlav N, et al. Dose-adjusted EPOCH chemotherapy for untreated large B-cell lymphomas: a pharmacodynamic approach with high efficacy. Blood. 2002;99(8):2685-93.

28. Wilson WH, Gutierrez M, O'Connor P, Frankel S, Jaffe E, Chabner BA, et al., editors. The role of rituximab and chemotherapy in aggressive B-cell lymphoma: a preliminary report of dose-adjusted EPOCH-R. Seminars in oncology; 2002: Elsevier.

29. Wilson WH, Dunleavy K, Pittaluga S, Hegde U, Grant N, Steinberg SM, et al. Phase II study of doseadjusted EPOCH-rituximab in untreated diffuse large B-cell lymphoma with analysis of germinal center and post-germinal center biomarkers. Journal of clinical oncology: official journal of the American Society of Clinical Oncology. 2008;26(16):2717.

30. Zuze T, Painschab MS, Seguin R, Kudowa E, Kaimila B, Kasonkanji E, et al. Plasmablastic lymphoma in Malawi. Infectious agents and cancer. 2018;13(1):22.

31. Sissolak G, Juritz J, Sissolak D, Wood L, Jacobs P. Lymphoma-emerging realities in sub-Saharan Africa. Transfusion and Apheresis Science. 2010;42(2):141-50.

32. Orem J, Maganda A, Mbidde EK, Weiderpass E. Clinical characteristics and outcome of children with Burkitt lymphoma in Uganda according to HIV infection. Pediatric blood \& cancer. 2009;52(4):455-8.

33. Bishop PC, Rao VK, Wilson WH. Burkitt's lymphoma: molecular pathogenesis and treatment. Cancer investigation. 2000;18(6):574-83. 
34. Smeland S, Blystad A, Kvaløy S, Ikonomou I, Delabie J, Kvalheim G, et al. Treatment of

Burkitt's/Burkitt-like lymphoma in adolescents and adults: a 20-year experience from the Norwegian

Radium Hospital with the use of three successive regimens. Annals of oncology. 2004;15(7):1072-8. 35. https://www.nccn.org/professionals/physician_gls/default.aspx (Accessed on 07 February 2020). [

\section{Table 3}

Table 3: PREDICTORS OF SURVIVAL

\begin{tabular}{|c|c|c|c|c|}
\hline \multirow[t]{2}{*}{ Variable } & \multicolumn{2}{|c|}{ Univariable } & \multicolumn{2}{|c|}{ Multivariable } \\
\hline & CHR (95\%CI) & P-Value & AHR (95\%CI) & P-Value \\
\hline Age in years & $1.0(0.98-1.05)$ & 0.32 & $1.0(0.96-1.04)$ & 0.95 \\
\hline Com Mol & $1.2(0.64-2.24)$ & 0.57 & $1.6(0.76-3.32)$ & 0.22 \\
\hline Study arm: EPOCH & $0.4(0.10-1.78)$ & 0.24 & $0.6(0.13-2.84)$ & 0.52 \\
\hline $\begin{array}{r}\text { ECOG } \\
0-2\end{array}$ & & & & \\
\hline $3-4$ & $3.4(1.10-8.82)$ & 0.01 & $1.7(0.55-5.26)$ & 0.36 \\
\hline Not assessed & $2.3(1.01-5.05)$ & 0.05 & $1.5(0.60-3.80)$ & 0.39 \\
\hline BMI & & & & \\
\hline $\begin{array}{l}<18.5 \mathrm{Kg} / \mathrm{m}^{2} \\
18.5-24.9 \mathrm{~kg} / \mathrm{m}^{2} \\
\geq 25 \mathrm{~kg} / \mathrm{m}^{2}\end{array}$ & $\begin{array}{l}0.4(0.20-0.83) \\
0.5(0.23-1.33)\end{array}$ & $\begin{array}{l}0.01 \\
0.19\end{array}$ & $\begin{array}{l}0.4(0.18-0.89) \\
0.6(0.21-2.02)\end{array}$ & $\begin{array}{l}0.03 \\
0.45\end{array}$ \\
\hline
\end{tabular}

\section{Lymphoma stage}

Early stage

Late stage

$1.8(0.76-4.04)$

0.19

$1.6(0.58-4.60)$

0.35

Not assessed

$1.5(0.49-4.32)$

0.50

$1(0.28-3.94)$

0.95

\section{Type of lymphoma}

Diffuse large B-cell lymphoma

Diffuse Large cell lymphoma

Plasmablastic lymphoma

$1.2(0.58-2.63)$

0.58

$1.0(0.39-2.43)$

0.95

NHL Other

$2.1(0.58-7.75)$

0.25

$1.4(0.30-6.02)$

0.69

Burkitt's

$2.5(0.84-7.28)$

0.10

$1.7(0.52-5.74)$

0.37

Burkitt's

$1.0(0.12-7.45)$

0.96

$0.3(0.03-3.45)$

0.33

Presence of B-symptoms

$$
0.9(0.47-1.63) \quad 0.67
$$

$0.9(0.44-1.96)$

0.85

Presence of comorbidity
$0.7(0.24-1.91)$
0.46
$0.9(0.28-2.69)$
0.81

Chemotherapy cycles received $<6$

$\geq 6$

$0.2(0.11-0.43)<0.001 \quad 0.2(0.10-0.47) \quad<0.001$

Note: AHR: Adjusted Hazard Ratio, BMI: Body Mass Index, CHR: Crude Hazard Ratio, ECOG: Eastern Cooperative Oncology Group 
Figures

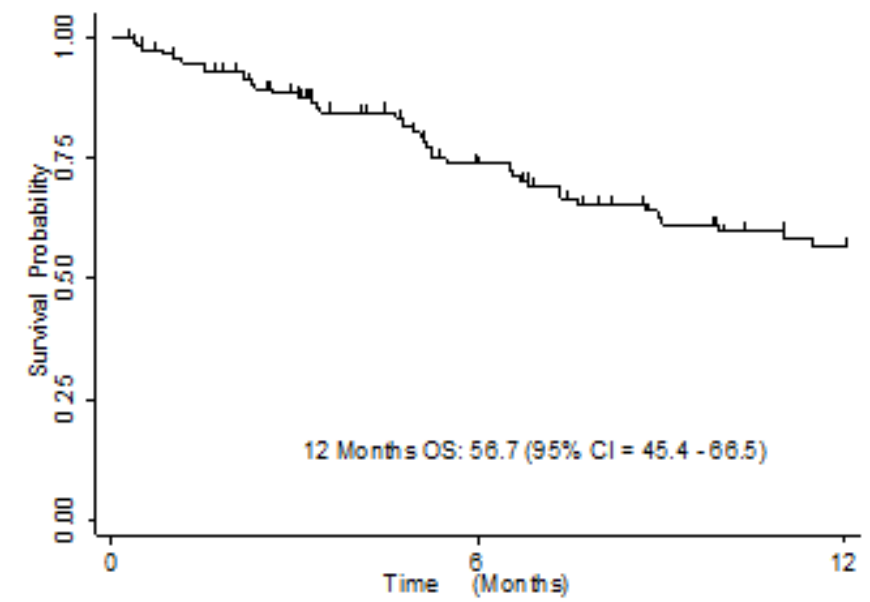

No. at risk

120

65

36

Panel A: Overall survival for the entire study population

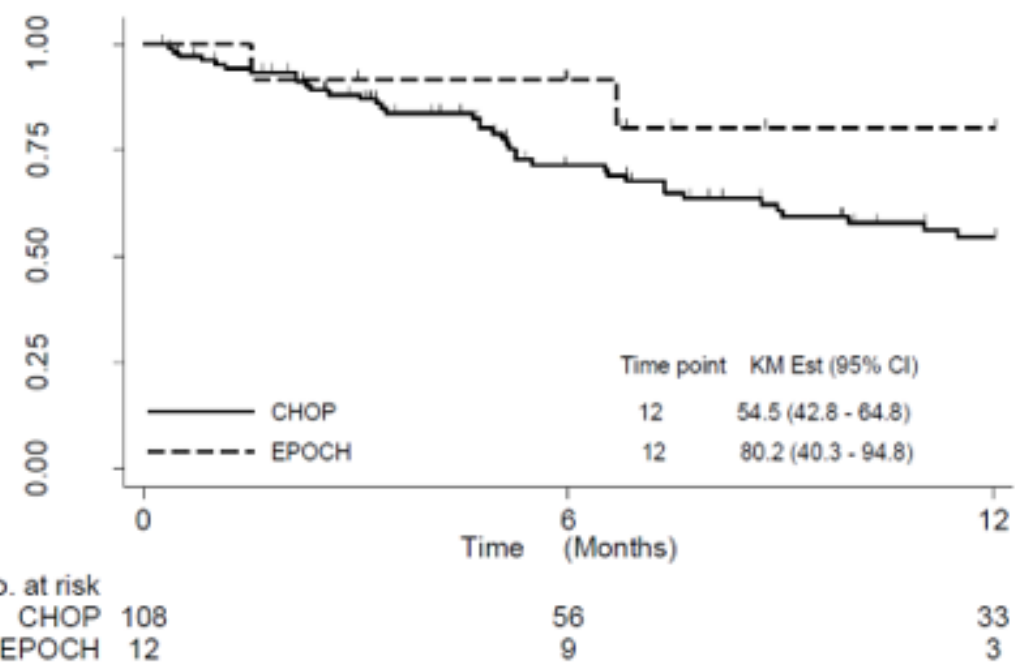

Panel B: Overall survival by treatment regimen

Figure 1

Overall survival graphs

\section{Supplementary Files}

This is a list of supplementary files associated with this preprint. Click to download.

- EPOCHDatasetCodeBook23Mar2020.log

- SharedDatasetJournal23Mar2020.rar

- EPOCHDOFILE23Mar2020.do 